\title{
Safe regions of miniscrew implantation for distalization of mandibular dentition with CBCT
}

\author{
Haibo Liu' ${ }^{1 \dagger}$, Xiaoxue $\mathrm{Wu}^{2 \dagger}$, Jun $\operatorname{Tan}^{1}$ and Xiao $\mathrm{Li}^{i^{*}}$ (D)
}

\begin{abstract}
Background: To assess the anatomy of the mandibular buccal shelf (MBS) with cone-beam computed tomography $(C B C T)$ and to identify the region of miniscrew implantation for the distalization of mandibular dentition.

Materials and methods: The MBS was assessed in 80 patients at four regions as follows: (i) between the buccal root of the mandibular second premolar and the mesiobuccal root of the first molar ( $\left(L 5_{b}-L \sigma_{m b}\right)$, (ii) between the mesiodistal root of the first molar $\left(L \sigma_{\mathrm{mb}}-\mathrm{L} \sigma_{\mathrm{db}}\right)$, (iii) between the distobuccal root of the first molar and the mesiobuccal root of the second molar $\left(L 6_{\mathrm{db}}-L 7_{\mathrm{mb}}\right)$, and (iv) between the mesiodistal roots of the second molar $\left(\mathrm{L} 7_{\mathrm{mb}}-\mathrm{L} 7_{\mathrm{db}}\right)$. The buccal alveolar bone thickness, the narrowest inter-radicular space at the buccal side of the roots, and the distance between the implantation site and the mandibular neural tube were measured at horizontal planes of 3,5,7, and $9 \mathrm{~mm}$ from the alveolar crest.

Results: The buccal alveolar bone thickness increased from the premolar to the molar and from the crest edge to the mandibular roots. The $L 7 \mathrm{mb}-\mathrm{L} 7_{\mathrm{db}}$ region had the thickest buccal alveolar bone of $7.61 \mathrm{~mm}$ at a plane of $9 \mathrm{~mm}$. The buccal inter-radicular spaces were smallest in the $L 7_{\mathrm{mb}}-L 7_{\mathrm{db}}$ region and greatest in the $L 6_{\mathrm{db}}-L 7_{\mathrm{mb}}$ region. The distances from the implantation site to the mandibular neural tube at planes of $3,5,7$, and $9 \mathrm{~mm}$ were all $>13 \mathrm{~mm}$ from the $L 6$ region to the $L 7$ region.
\end{abstract}

Conclusions: The $L \sigma_{d b}-L 7_{m b}$ region should be the first choice for miniscrew implantation in the MBS for the distalization of mandibular dentition.

Keywords: Mandibular buccal shelf, Cone-beam computed tomography, Miniscrew, Mandibular dentition

\section{Background}

To correct tooth movement, miniscrews are routinely implanted in various positions in the maxilla and mandible, including the inter-radicular space, infrazygomatic crest, paramedian palate, and retromolar area [1-3]. Inter-radicular miniscrews are most commonly used, but their insertion is often problematic in the posterior mandible [4]. Recently, the mandibular buccal shelf (MBS) has been used as the insertion site for orthodontic

\footnotetext{
* Correspondence: 48587172@qq.com

${ }^{\dagger}$ Haibo Liu and Xiaoxue Wu contributed equally to this work and should be considered co-first authors.

${ }^{1}$ Department of Stomatology, General Hospital of Southern Theater Command of the Chinese People's Liberation Army (Guangzhou Liuhuaqiao Hospital), No.111, Liuhua road, Guangzhou 510016, Guangdong, China Full list of author information is available at the end of the article
}

miniscrews, as this region offers sufficient bone and adequate bone quality for miniscrew insertion [5].

Distal en masse movement of mandibular dentitions is quite effective in patients with class III malocclusions. Prior to the introduction of the miniscrew in the field of orthodontics, it was difficult to move mandibular dentitions. With the aid of a miniscrew inserted in the MBS region, mandibular dentitions can be successfully moved [6-8] (Fig. 1).

The MBS includes the proximal area of the first molar, which is between the first and second molars, as well as the distal area of the second molar. The MBS offers improved stability, and it associates with a lower failure rate for miniscrew insertion [9]. However, there are various anatomical differences in this region. Unfortunately, few studies have examined the anatomy of the MBS. The objective of this study was to analyze the buccal 

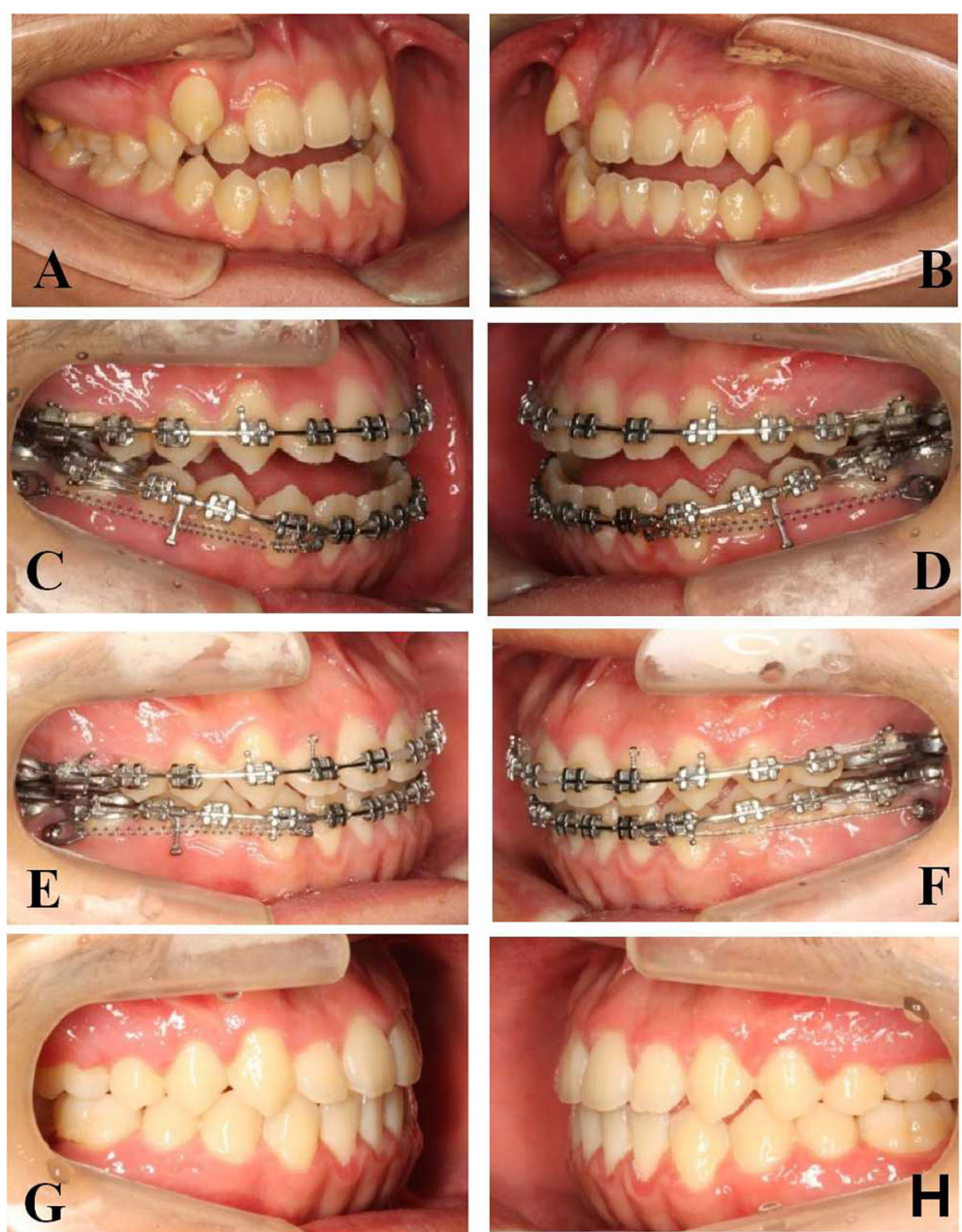

Fig. 1 Images for distalization of the entire mandibular dentition with miniscrews inserted in the MBS region. $\mathbf{a}$, $\mathbf{b}$ Intraoral images before treatment. c-f Miniscrew insertion for the distalization of mandibular dentition. $\mathbf{g}, \mathbf{h}$ Intraoral images after treatment

bone thickness and buccal inter-radicular distance, as well as the relationship between the miniscrew and the inferior alveolar nerve in order to determine the most suitable MBS sites for miniscrew insertion.

\section{Materials and methods \\ Samples}

Cone-beam computed tomography (CBCT) images of 80 patients (30 males and 50 females; average age $26 \pm 7$ years) were obtained from the Department of Orthodontics, Stomatology Hospital of Guangzhou Medical University. The CBCT images were collected from October 2015 to January 2018 and fulfilled the following criteria: patients aged 18 to 37 years with full permanent dentition and evidence of fully erupted mandibular second molars (except third molars), no impacted teeth, no history of previous orthodontic treatment, and no severe crowding were included, whereas those with periodontal disease and craniofacial anomalies or systemic diseases were excluded.

\section{Methods}

Eighty CBCT images were obtained with a CBCT instrument (NewTom, Verona, Italy) at $110 \mathrm{kV}$ and $0.07 \mathrm{~mA}$. The CBCT images were formatted into standard DICOM images and reconstructed into continuous slices of $0.3 \mathrm{~mm}$ in thickness. All images were analyzed by Mimics (version 10.0; Materialise, Leuven, Belgium) (Fig. 2).

To assess the safe regions of the miniscrews implanted in the MBS for the distalization of mandibular dentition, four sites were measured in the buccal shelf on each side as follows: (i) between the buccal root of the mandibular second premolar and the mesiobuccal root of the first molar $\left(\mathrm{L} 5_{\mathrm{b}}-\mathrm{L} 6_{\mathrm{mb}}\right)$, (ii) between the mesiodistal roots of the first molar $\left(\mathrm{L} 6_{\mathrm{mb}}-\mathrm{L} 6_{\mathrm{db}}\right)$, (iii) between the distobuccal root of the first molar and the mesiobuccal root of the second molar $\left(\mathrm{L} 6_{\mathrm{db}}-\mathrm{L} 7_{\mathrm{mb}}\right)$, and (iv) between the 


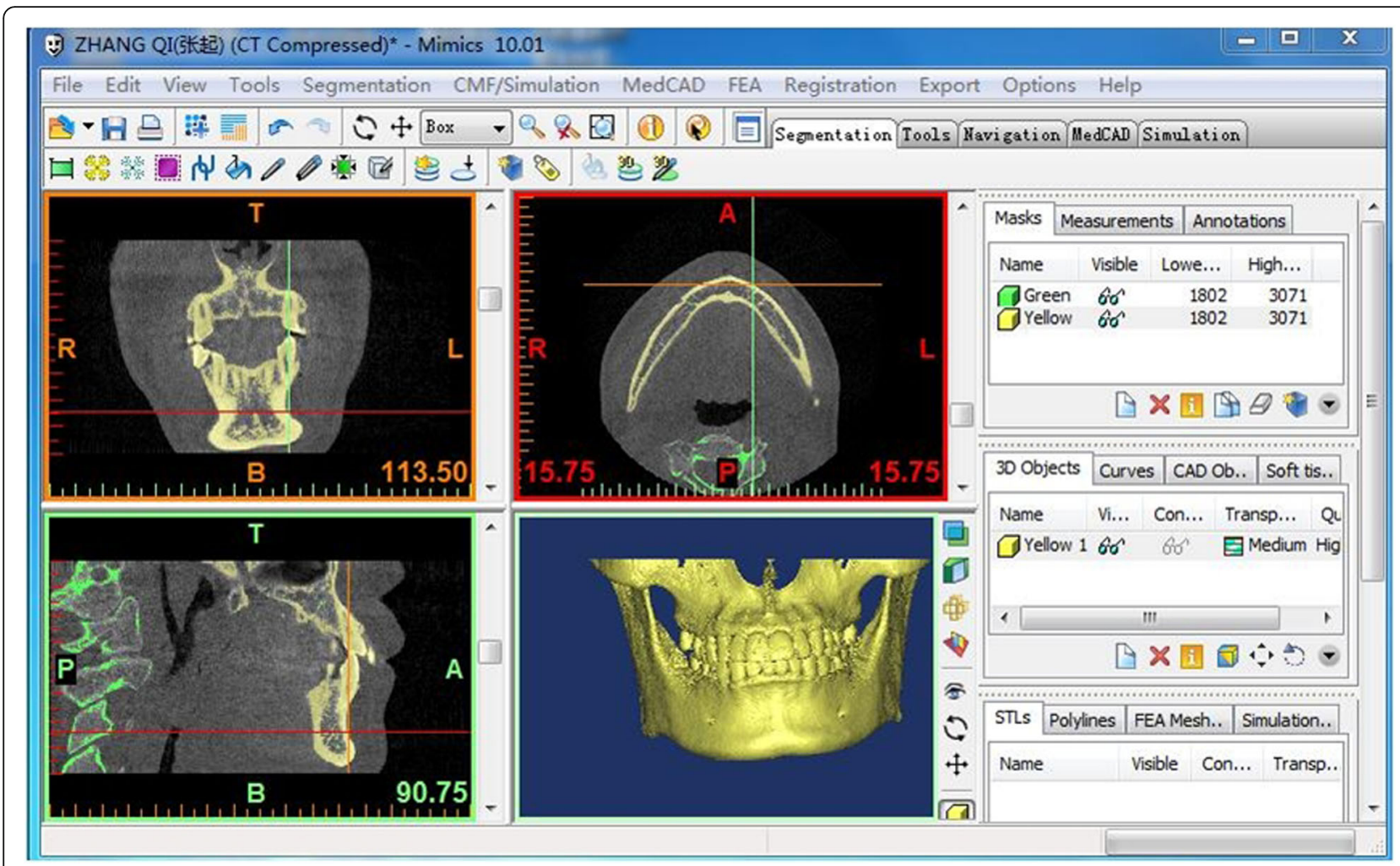

Fig. 2 CBCT images of three slices and 3D reconstruction by Mimics

mesiodistal roots of the second molar $\left(\mathrm{L} 7_{\mathrm{mb}}-\mathrm{L} 7_{\mathrm{db}}\right)$. The buccal alveolar bone thickness, the narrowest interradicular space at the buccal side of the roots, and the distance between the implantation site and the mandibular neural tube were measured.

For measuring the buccal alveolar bone thickness, the patient's mandible was oriented in all three spatial planes. First, the base plane was determined, the highest point of the right and left alveolar crest in the first molar and the highest point of the right alveolar crest in the second molar were identified, the base plane was reoriented in order to pass through these three highest points. Second, sagittal and coronal images were adjusted so that the base plane was parallel to the frame's border. The mid-sagittal plane was centered on the axial slice. The buccal alveolar bone thicknesses of these regions were measured at

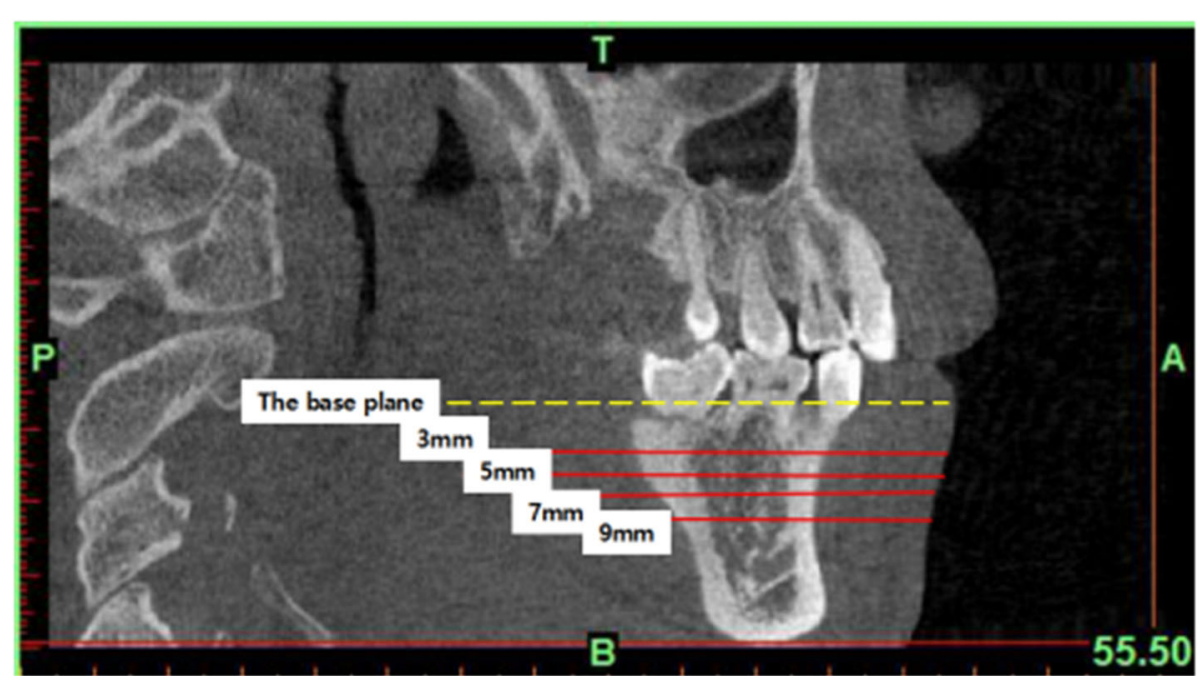

Fig. 3 Reference lines for planes of 3,5,7, and $9 \mathrm{~mm}$ below the measurement base plane (alveolar crest edge) in the sagittal view 
horizontal planes of 3, 5, 7, and $9 \mathrm{~mm}$ from the alveolar crest, parallel to the base plane (Figs. 3 and 4).

The narrowest inter-radicular space at the buccal side of the roots was measured at $\mathrm{L} 5_{\mathrm{b}}-\mathrm{L} 6_{\mathrm{mb}}, \mathrm{L} 6_{\mathrm{mb}}-\mathrm{L} 6_{\mathrm{db}}, \mathrm{L} 6_{\mathrm{db}}-$ $\mathrm{L} 7_{\mathrm{mb}}$, and $\mathrm{L} 7_{\mathrm{mb}}-\mathrm{L} 7_{\mathrm{db}}$ regions at planes of 3, 5, 7, and 9 $\mathrm{mm}$ from the buccal alveolar crest edge (Figs. 3 and 5).

The distance between the implantation site and the mandibular neural tube was measured at $\mathrm{L} 6_{\mathrm{mb}}-\mathrm{L} 6_{\mathrm{db}}$ or $\mathrm{L} 7_{\mathrm{mb}}-\mathrm{L} 7_{\mathrm{db}}$ regions at the coronal plane which was exactly through the midpoint of the mesial and distal direction of the first or second molar.

Miniscrews were implanted at planes of 3,5, 7, and 9 $\mathrm{mm}$ from the alveolar crest at the coronal plane, and then the distance from the implantation site to the mandibular neural tube was measured (Fig. 6).

\section{Statistical analysis}

SPSS 17.0 (Chicago, IL, USA) was used for statistical analysis. $P$ values $<0.05$ were considered significant. Measurements and data analysis were performed by the same investigator. Ten out of 80 volumetric tomographic images were randomly selected and repeated twice at an interval of 2 weeks by the same investigator. No statistical difference was found between the repeated measurements. Intraclass correlations showed high reliability $(r=0.8)$. A paired Student's $t$ test was used to test for differences between the left and right sides. No statistically significant differences were found $(P>0.05)$. The Kruskal-Wallis $H$ test was applied to evaluate the differences in the buccal alveolar bone thickness, the narrowest inter-radicular space, and the distance from the implantation site to the mandibular neural tube in each measured region in each slice.

\section{Results}

The buccal alveolar bone thicknesses at planes of 3, 5, 7, and $9 \mathrm{~mm}$ at four regions are shown in Table 1. There were significant differences in buccal alveolar bone thickness among $\mathrm{L} 5_{\mathrm{b}}-\mathrm{L} 6_{\mathrm{mb}}, \mathrm{L} 6_{\mathrm{mb}}-\mathrm{L} 6_{\mathrm{db}}, \mathrm{L} 6_{\mathrm{db}}-\mathrm{L} 7_{\mathrm{mb}}$, and $\mathrm{L} 7_{\mathrm{mb}}-\mathrm{L} 7_{\mathrm{db}}$ regions within the same plane $(P<0.05)$. The buccal alveolar bone thickness increased from the premolar to the molar. Although no significant difference was observed among different adjacent planes within the same region $(P>0.05)$, there were significant differences at the nonadjacent planes within the same region $(P<0.05)$. The buccal alveolar bone thickness increased from the crest edge to the mandibular root. The $\mathrm{L} 5 \mathrm{~b}-\mathrm{L} 6_{\mathrm{mb}}$ region had the thinnest buccal alveolar bone of $1.02 \mathrm{~mm}$ at the plane of $3 \mathrm{~mm}$, and the $\mathrm{L} 7_{\mathrm{mb}}-\mathrm{L} 7 \mathrm{db}$ region had the thickest buccal alveolar bone of $7.61 \mathrm{~mm}$ at the plane of $9 \mathrm{~mm}$.

The narrowest buccal inter-radicular spaces at planes of $3,5,7$, and $9 \mathrm{~mm}$ at four sites are shown in Table 2. There were significant differences in the narrowest buccal spaces between the roots of different teeth and between the roots of the same tooth $(P<0.05)$. The inter-radicular space was significantly greater in $\mathrm{L} 5_{\mathrm{b}}-\mathrm{L} 6_{\mathrm{mb}}$ and $\mathrm{L} 6_{\mathrm{db}}-\mathrm{L} 7_{\mathrm{mb}}$ regions than that in $\mathrm{L} 6_{\mathrm{mb}}-\mathrm{L} 6_{\mathrm{db}}$ and $\mathrm{L} 7_{\mathrm{mb}}-\mathrm{L} 7_{\mathrm{db}}$ regions at the same plane. The narrowest buccal inter-radicular space increased from the crest edge to the mandibular root within the same region. The buccal inter-radicular spaces were the narrowest in the $\mathrm{L} 7_{\mathrm{mb}}-\mathrm{L} 7_{\mathrm{db}}$ region and the widest in the $\mathrm{L} 6_{\mathrm{db}}-\mathrm{L} 7_{\mathrm{mb}}$ region. The $\mathrm{L} 6_{\mathrm{db}}-\mathrm{L} 7_{\mathrm{mb}}$

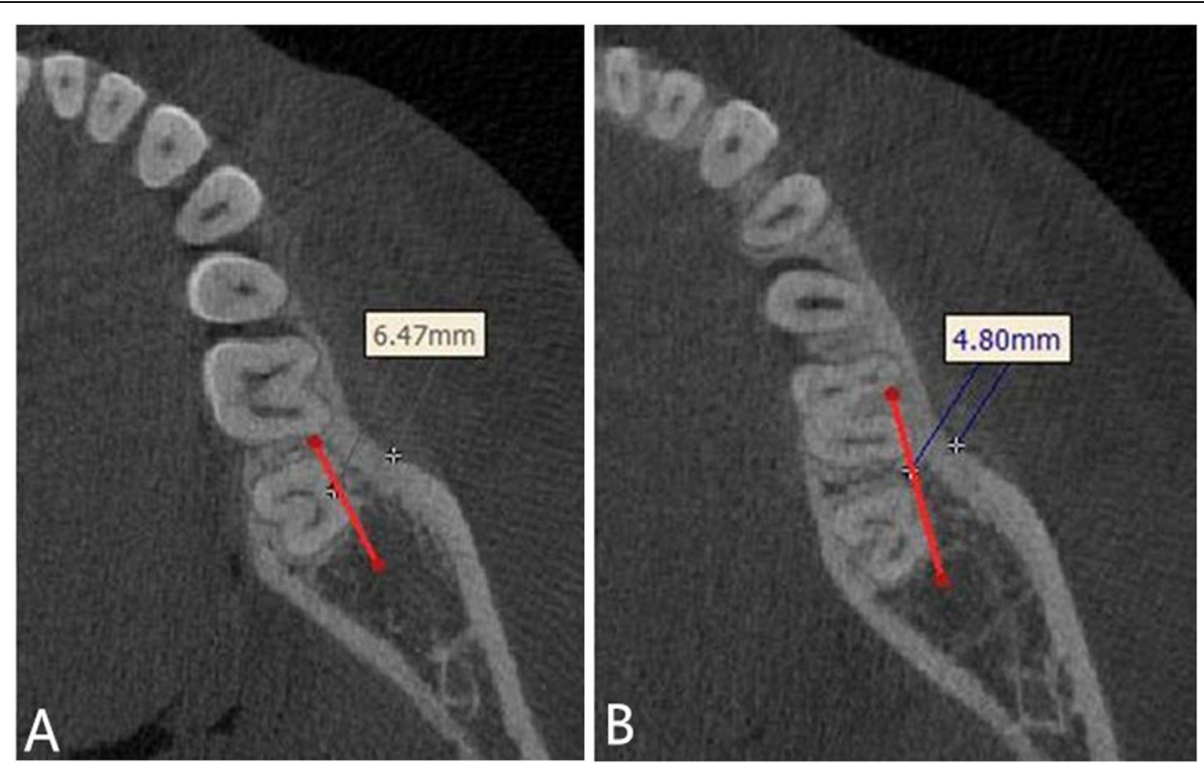

Fig. 4 Measurement of buccal alveolar bone thickness (right-hand side). a A thickness of $5 \mathrm{~mm}$ from the alveolar crest between the mesiodistal roots of the second molar $\left(L 7_{\mathrm{mb}}-\mathrm{L} 7_{\mathrm{db}}\right) \cdot \mathbf{b}$ A thickness of $7 \mathrm{~mm}$ from the alveolar crest between the first and second molar $\left(L 6_{\mathrm{db}}-L 7_{\mathrm{mb}}\right)$ 

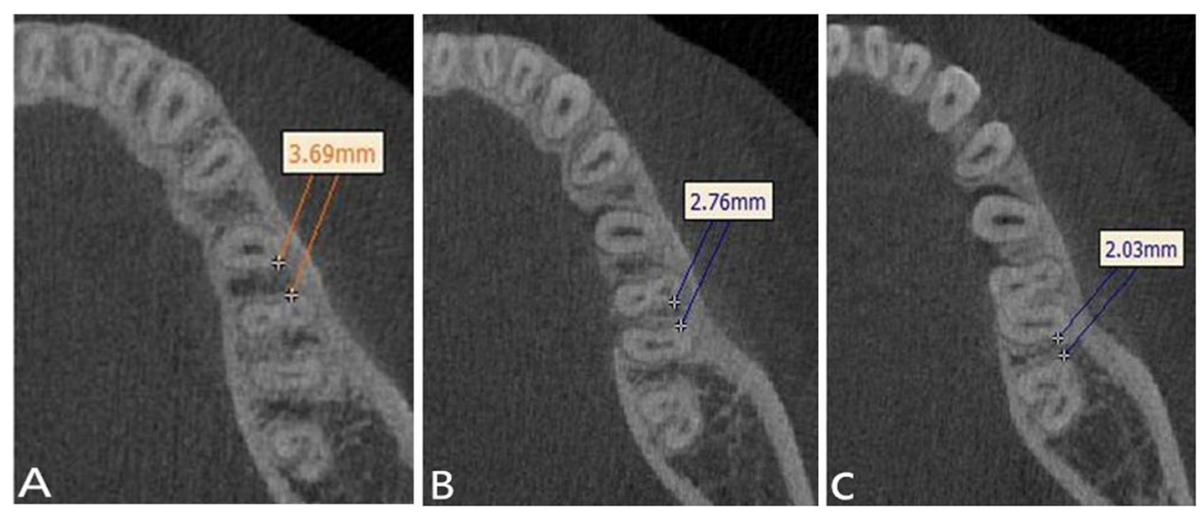

Fig. 5 Measurement of the narrowest inter-radicular space at the buccal side of the roots (right-hand side). a A space of $7 \mathrm{~mm}$ from the alveolar crest between the second premolar and the first molar $\left(L 5_{b}-L \sigma_{m b}\right)$. b A space of $7 \mathrm{~mm}$ from the alveolar crest between the mesiodistal roots of the first molar $\left(L \sigma_{\mathrm{mb}}-\mathrm{L} \sigma_{\mathrm{db}}\right)$. c A space of $7 \mathrm{~mm}$ from the alveolar crest between the first and second molar ( $\left(L 6_{\mathrm{db}}-L 7_{\mathrm{mb}}\right)$

region had the narrowest buccal inter-radicular space of > $3.5 \mathrm{~mm}$ at planes of 7 and $9 \mathrm{~mm}$.

No significant difference in distance from the implantation site to the mandibular neural tube was observed for $\mathrm{L} 6_{\mathrm{mb}}-\mathrm{L} 6_{\mathrm{db}}$ and $\mathrm{L} 7_{\mathrm{mb}}-\mathrm{L} 7_{\mathrm{db}}$ regions $(P>0.05)$ (Table 3). The distances from the implantation site to the mandibular neural tube were all $>13 \mathrm{~mm}$ at planes of 3, 5, 7, and $9 \mathrm{~mm}$ for L6 and L7 regions.

\section{Discussion}

The use of miniscrew has grown in popularity over the years because of its ability to provide absolute anchorage [10]. Distalization of the entire mandibular dentition is a viable way to correct a class III anteroposterior relationship (a negative overjet or an edge-to-edge occlusion) with miniscrews implanted in the MBS and dental and skeletal discrepancies of many patients could get dento-alveolar compensation [6]. However, the success of the method is closely related to the anatomical structures of the MBS. It is also critical to select an appropriate site in the MBS for miniscrew implantation. This site should provide good stability for the distalization of mandibular dentition without affecting the distal movement of teeth and the overall periodontal health. Although several investigators have evaluated cortical bone thickness and bone width by $\mathrm{CBCT}[5,11,12]$, a threedimensional evaluation of safe region of miniscrew
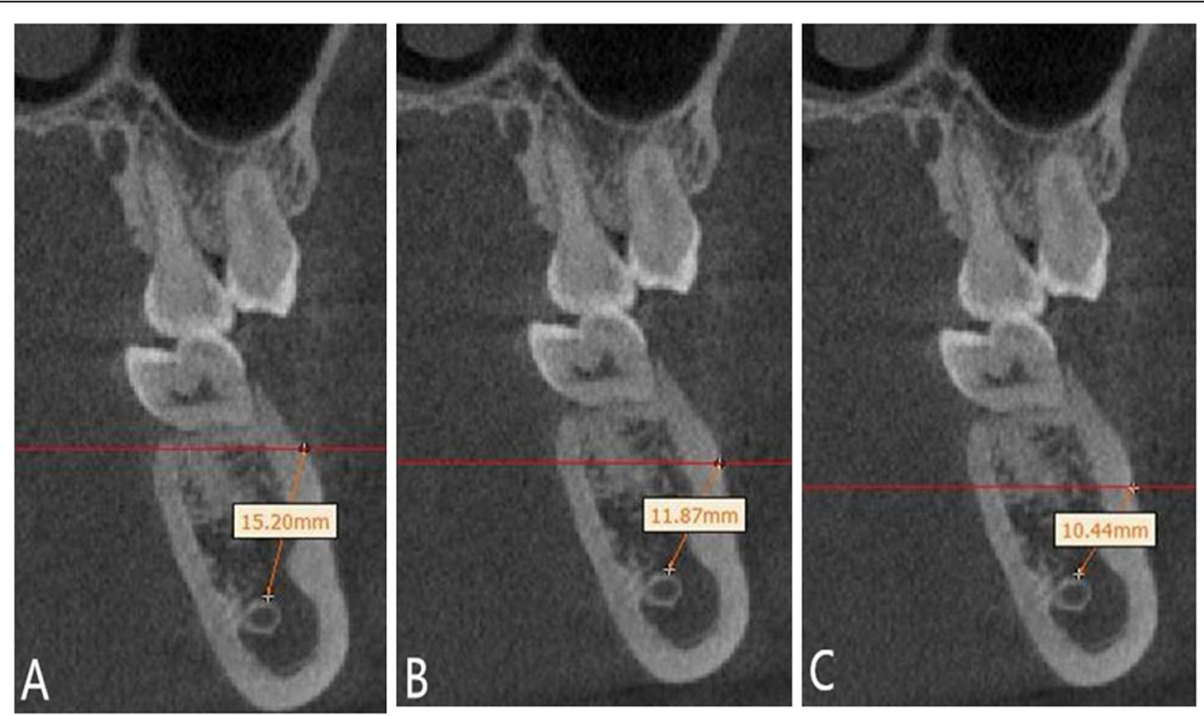

Fig. 6 Measurement of the distance between the implantation site and the mandibular neural tube. a The implantation site at the plane of $5 \mathrm{~mm}$ from the alveolar crest and between the mesiodistal roots of the first molar ( $\left(\sigma_{\mathrm{mb}}-L \sigma_{\mathrm{db}}\right)$. $\mathbf{b}$ The implantation site at the plane of $7 \mathrm{~mm}$ from the alveolar crest and between the mesiodistal roots of the first molar $\left(L 6_{m b}-L 6_{d b}\right)$. $\mathbf{c}$ The implantation site at the plane of $9 \mathrm{~mm}$ from the alveolar crest and between the mesiodistal roots of the first molar $\left(L \sigma_{m b}-L \sigma_{d b}\right)$ 
Table 1 Buccal alveolar bone thicknesses (in millimeters: mean \pm SD) at the planes of $3,5,7$, and $9 \mathrm{~mm}$

\begin{tabular}{cllll}
\hline & $3 \mathrm{~mm}$ & $5 \mathrm{~mm}$ & $7 \mathrm{~mm}$ & $9 \mathrm{~mm}$ \\
\hline $\mathrm{L} 5_{\mathrm{b}}-\mathrm{L} \sigma_{\mathrm{mb}}$ & 1.02 & 1.36 & 2.51 & 3.93 \\
$\mathrm{SD}$ & 0.37 & 0.46 & 0.88 & 0.63 \\
$\mathrm{~L} \sigma_{\mathrm{mb}}-\mathrm{L} \sigma_{\mathrm{db}}$ & 1.80 & 2.15 & 3.29 & 4.86 \\
$\mathrm{SD}$ & 0.43 & 0.58 & 0.85 & 1.17 \\
$\mathrm{~L} \sigma_{\mathrm{db}}-\mathrm{L} 7_{\mathrm{mb}}$ & 2.88 & 3.45 & 5.07 & 6.39 \\
$\mathrm{SD}$ & 0.55 & 0.71 & 0.92 & 1.24 \\
$\mathrm{~L} 7_{\mathrm{mb}}-\mathrm{L} 7_{\mathrm{db}}$ & 3.86 & 4.92 & 6.17 & 7.61 \\
$\mathrm{SD}$ & 0.51 & 0.96 & 1.25 & 1.01 \\
\hline
\end{tabular}

$L S_{b}$ buccal root of the second premolar, $L \sigma_{m b}$ mesiobuccal root of the first molar, $L \sigma_{d b}$ distobuccal root of the first molar, $L 7_{m b}$ mesiobuccal root of the second molar, $L 7_{d b}$ distobuccal root of the second molar

insertion in the MBS for mandibular dentition distalization has never been performed.

The MBS provides sufficient bone, thereby allowing miniscrew insertion on the buccal side of the tooth root and avoiding screw to root contact during distalization [13]. In this study, the width of the buccal alveolar in the posterior tooth area was significantly thicker than that in the anterior tooth area; therefore, the $\mathrm{L}_{\mathrm{db}}-\mathrm{L} 7_{\mathrm{mb}}$ and $\mathrm{L} 7_{\mathrm{mb}}-\mathrm{L} 7_{\mathrm{db}}$ regions were safer than the $\mathrm{L} 6_{\mathrm{mb}}-\mathrm{L} 6_{\mathrm{db}}$ and $\mathrm{L} 5_{\mathrm{db}}-\mathrm{L} 6_{\mathrm{mb}}$ regions for miniscrew insertion. To obtain sufficient orthodontic loading and stability, the length of the miniscrew biting depth in the bone should be at least $6 \mathrm{~mm}$ when the entire mandibular dentition was distalizated [14]. The narrowest buccal inter-radicular space in the $\mathrm{L} 7 \mathrm{mb}-\mathrm{L} 7_{\mathrm{db}}$ region was significantly lower than that of the $\mathrm{L}_{\mathrm{db}}-\mathrm{L} 7_{\mathrm{mb}}$ region at all planes. Considering the risk of miniscrew and root contact, the $\mathrm{L}_{\mathrm{db}}-\mathrm{L} 7_{\mathrm{mb}}$ region is the most reasonable and safest for miniscrew implantation in the MBS for the distalization of the entire mandibular dentition.

Although no signs or symptoms caused by root contact with miniscrews during mesiodistal movement of

Table 2 Buccal narrowest inter-radicular space (in millimeters: mean \pm SD) at the planes of 3,5,7, and $9 \mathrm{~mm}$

\begin{tabular}{cllll}
\hline & $3 \mathrm{~mm}$ & $5 \mathrm{~mm}$ & $7 \mathrm{~mm}$ & $9 \mathrm{~mm}$ \\
\hline $\mathrm{L} 5_{\mathrm{b}}-\mathrm{L} 6_{\mathrm{mb}}$ & 1.94 & 2.69 & 3.31 & 3.84 \\
$\mathrm{SD}$ & 0.74 & 0.82 & 0.91 & 1.19 \\
$\mathrm{~L} 6_{\mathrm{mb}}-\mathrm{L} 6_{\mathrm{db}}$ & 0.99 & 1.75 & 2.29 & 2.54 \\
$\mathrm{SD}$ & 0.53 & 0.56 & 0.67 & 1.03 \\
$\mathrm{~L} 6_{\mathrm{db}}-\mathrm{L} 7_{\mathrm{mb}}$ & 2.78 & 3.22 & 3.92 & 4.97 \\
$\mathrm{SD}$ & 1.04 & 1.54 & 1.94 & 2.36 \\
$\mathrm{~L} 7_{\mathrm{mb}}-\mathrm{L} 7_{\mathrm{db}}$ & 0.79 & 1.30 & 1.39 & 2.04 \\
$\mathrm{SD}$ & 0.46 & 0.77 & 0.87 & 0.88 \\
\hline
\end{tabular}

$L S_{b}$ buccal root of the second premolar, $L \sigma_{m b}$ mesiobuccal root of the first molar, $L \sigma_{d b}$ distobuccal root of the first molar, $L 7_{m b}$ mesiobuccal root of the second molar, $L 7_{d b}$ distobuccal root of the second molar
Table 3 Distance from the implantation site to the mandibular neural tube (in millimeters: mean \pm SD) at the planes of 3, 5, 7, and $9 \mathrm{~mm}$

\begin{tabular}{|c|c|c|c|c|}
\hline & \multicolumn{2}{|c|}{$\mathrm{L} \sigma_{\mathrm{mb}}-\mathrm{L} \sigma_{\mathrm{db}}$} & \multicolumn{2}{|c|}{$\mathrm{L} 7_{\mathrm{mb}}-\mathrm{L} 7_{\mathrm{db}}$} \\
\hline & $x$ & SD & $x$ & SD \\
\hline $3 \mathrm{~mm}$ & 18.73 & 2.51 & 18.34 & 2.21 \\
\hline $5 \mathrm{~mm}$ & 16.27 & 1.88 & 16.29 & 2.13 \\
\hline $7 \mathrm{~mm}$ & 14.78 & 1.78 & 14.98 & 2.16 \\
\hline $9 \mathrm{~mm}$ & 13.40 & 1.70 & 13.72 & 2.19 \\
\hline
\end{tabular}

the molar have been reported, screw and root contact during insertion of miniscrews for orthodontic anchorage would increase the failure rate $[13,15]$. In addition, a sufficient buccal bone mass and a large screw-root distance will further improve the success rate of miniscrews. Our results show that the mean values of the buccal alveolar bone and the inter-radicular space in the $\mathrm{L} 6_{\mathrm{db}}-\mathrm{L} 7_{\mathrm{mb}}$ region were $6.39 \mathrm{~mm}$ and $4.97 \mathrm{~mm}$ at a plane of $9 \mathrm{~mm}$, respectively, with wider measurements at planes $<9 \mathrm{~mm}$. As a minimum of $1 \mathrm{~mm}$ of alveolar bone around the screw is sufficient for good periodontal health [10], and considering that the diameters of most miniscrews are 1.2 to $2.3 \mathrm{~mm}$ [10], we conclude that it is safe for miniscrews to be inserted in the $\mathrm{L}_{\mathrm{db}}-\mathrm{L} 7_{\mathrm{mb}}$ region at and below a plane of $9 \mathrm{~mm}$.

Miniscrew selection depends on multiple factors, including the insertion site, miniscrew material, cortical bone thickness, inter-radicular space, and method of miniscrew insertion [16]. On the one hand, the cortical bone thickness of the MBS was significantly greater than that of the other insertion sites. The anatomical features and loading force for the distilization of mandibular dentition indicated that miniscrews of greater sizes should be inserted in the buccal shelf. Therefore, we recommend using miniscrews $2 \mathrm{~mm}$ in diameter for implantation in the MBS to avoid excessive insertion torque and eventual fracture. On the other hand, systematic review revealed that the miniscrew length was closely related to the stability and success rate of the miniscrew. Crismani et al. showed that $8-\mathrm{mm}$ miniscrews were associated with a $22 \%$ higher success rate than $6-\mathrm{mm}$ ones [17]. In addition, the miniscrew length should be based on the location of adjacent anatomical structures (dental roots, nerves, and blood vessels) as well as the available bone depth. To avoid injury to vital anatomical structures during implantation, we evaluated the relationship between the inferior alveolar nerve and the implantation site. Our results showed that the distances from the implantation site to the mandibular neural tube were $>13 \mathrm{~mm}$ at a plane of $9 \mathrm{~mm}$. Considering other factors, we recommend using $10-\mathrm{mm}$ 
or $12-\mathrm{mm}$ miniscrews in the $\mathrm{L} 6_{\mathrm{db}}-\mathrm{L} 7_{\mathrm{mb}}$ region at a plane of $9 \mathrm{~mm}$. Of course, the miniscrew length should be shorter for smaller insertion sites.

Previous studies have reported the most favorable overall anatomic relationship for MBS orthodontic miniscrew placement to be at the level of the distobuccal cusp of the second molar, whereas the buccal bone and the cortical bone were the thickest in the MBS region $[12,18]$. Due to limitations caused by the non-wide opening of patients' mouths, the distal location of the insertion site can cause difficulties when accessing the site at the best angle. Furthermore, the thicker soft tissue can increase the failure rate of miniscrews [9]. Therefore, we still consider the $\mathrm{L} 6_{\mathrm{db}}-$ $\mathrm{L} 7 \mathrm{mb}$ region as the best site in the MBS for the distalization of mandibular dentition.

Due to the limitation in the number of samples, many factors that might affect the measurement of the MBS, such as ethnicity, vertical skeletal patterns, and gender, were not considered [19]. Moreover, the thickness and morphology of the soft tissue in the MBS should also be studied, because the mobility of the alveolar mucosa can affect long-term miniscrew stability [10]. As such, further experiments will be needed to confirm our findings.

\section{Conclusion}

According to an analysis of CBCT images, the region between the mandibular first and second molars $\left(\mathrm{L}_{\mathrm{db}}-\right.$ L7 $\mathrm{mb}$ ) should be the first choice for minisrew implantation in the buccal alveolar bone in the MBS for the distalization of the entire mandibular dentition.

\section{Abbreviations}

L5b: Buccal root of the mandibular second premolar; L6 6 b: Distobuccal root of the mandibular first molar; $L 6_{\mathrm{mb}}$ : Mesiobuccal root of the mandibular first molar; L7 $7_{\mathrm{db}}$ : Distobuccal root of the mandibular second molar;

$\mathrm{L} 7_{\mathrm{mb}}$ : Mesiobuccal root of the mandibular second molar; MBS: Mandibular buccal shelf

\section{Acknowledgements}

The study was supported by the Applied Basic Science Research Program through the Military Research Foundation of China (No. 2016-CGZ16C006) and Medical Science and Technology Research Foundation Project of Guang dong, China (A2019352). Thanks to Dr. Jun Tan for his help and support in the process of data review and manuscript revision.

\section{Authors' contributions}

$X \mathrm{~L}$ was the supervisor and designed the study. $\mathrm{HL}$ and $\mathrm{XW}$ drafted the manuscript and writing the manuscript. HL performed the statistical analysis and data analysis. JT contributed to search the literature and review the manuscript. All authors read and approved the final manuscript.

\section{Funding}

The Applied Basic Science Research Program through the Military Research Foundation of China (Grant 2016-CGZ16C006) provided financial support for the research.

\section{Availability of data and materials}

The data used to support the findings of this study are included within the article. The original data of each patient will also be used for research of other subjects. It is not convenient to release the data until the publication of the article. If necessary, the corresponding author can be asked for.

Ethics approval and consent to participate

The study was approved by the Institutional Review Board of the Stomatological Hospital of Air Force Military Medical University(2016048) and Guangzhou Medical University(2019038).

\section{Consent for publication}

All sample data are from the CBCT database of relevant hospitals. This study is of a retrospective nature, so informed consent was waived.

\section{Competing interests}

The authors declare that they have no competing interests.

\section{Author details}

${ }^{1}$ Department of Stomatology, General Hospital of Southern Theater Command of the Chinese People's Liberation Army (Guangzhou Liuhuaqiao Hospital), No.111, Liuhua road, Guangzhou 510016, Guangdong, China.

${ }^{2}$ Department of Orthodontics, Key Laboratory of Oral Medicine, Guangzhou Institute of Oral Disease, Stomatology Hospital of Guangzhou Medical University, Guangzhou 510140, Guangdong, China.

Received: 28 June 2019 Accepted: 1 November 2019

Published online: 09 December 2019

\section{References}

1. Chang HP, Tseng YC. Miniscrew implant applications in contemporary orthodontics. Kaohsiung J Med Sci. 2014;30(3):111-5.

2. Liu H, Wu X, Yang L, Ding Y. Safe zones for miniscrews in maxillary dentition distalization assessed with cone-beamcomputed tomography. Am J Orthod Dentofacial Orthop. 2017;151(3):500-6.

3. Poletti L, Silvera A, Ghislanzoni L. Dentoalveolar class III treatment using retromolar miniscrew anchorage. Prog Orthod. 2013;14(1):1-6.

4. Marquezan M, Mattos CT, Sant'Anna EF, et al. Does cortical thickness influence the primary stability of miniscrews? A systematic review and meta-analysis. Angle Orthod. 2014;84(6):1093-103.

5. Nucera R, Lo Giudice A, Bellocchio AM. Bone and cortical bone thickness of mandibular buccal shelf for mini-screw insertion in adults. Angle Orthod. 2017:87(5):745-51.

6. Jing Y, Han X, Guo Y. Nonsurgical correction of a Class III malocclusion in an adult by miniscrew-assisted mandibulardentition distalization. Am J Orthod Dentofacial Orthop. 2013;143(6):877-87

7. Chung KR, Kim SH, Choo H, Kook YA, Cope JB. Distalization of the mandibular dentition with mini-implants to correct a Class III malocclusion with a midline deviation. Am J Orthod Dentofacial Orthop. 2010;137(1):135-46.

8. Chen K. Class III malocclusion treated with distalization of the mandibular dentition with miniscrew anchorage: a 2-year follow-up. Am J Orthod Dentofacial Orthop. 2015;148(6):1043-53.

9. Chang C, Sean SY, Liu W, Roberts WE. Primary failure rate for 1680 extraalveolar mandibular buccal shelf mini-screws placed in movable mucosa or attached gingiva. Angle Orthodontist. 2015;85(6):905-10.

10. Alkadhimi A, Al-Awadhi EA. Miniscrews for orthodontic anchorage: a review of available systems. Journal of Orthodontics. 2018;45(2):102-14.

11. Elshebiny T, Palomo JM, Baumgaertel S. Anatomic assessment of the mandibular buccal shelf for miniscrew insertion in white patients. American Journal of Orthodontics and Dentofacial Orthopedics. 2018;153(4):505-11.

12. Veli I, Uysal T, Baysal A, et al. Buccal cortical bone thickness at miniscrew placement sites in patients with different vertical skeletal patterns. J Orofac Orthop. 2014;75(6):417-29.

13. Chen $\mathrm{YH}$, Chang $\mathrm{HH}$, Chen $\mathrm{YJ}$, et al. Root contact during insertion of miniscrews for orthodontic anchorage increases the failure rate: an animal study. Clinical Oral Implants Research. 2008;19(1):99-106.

14. Melsen B, Costa A. Immediate loading of implants used for orthodontic anchorage. Clin Orthod Res. 2000;3(1):23-8.

15. Poggio PM, Incorvati C, Velo S, Carano A. "Safe zones": a guide for miniscrew positioning in the maxillary and mandibular arch. Angle Orthodontist. 2006;76(2):191-7. 
16. Motoyoshi M, Yoshida T, Ono A, Shimizu N. Effect of cortical bone thickness and implant placement torque on stability of orthodontic mini-implants. Int J Oral Maxillofac Implants. 2007;22(5):779-84.

17. Crismani AG, Bertl MH, Celar AG, et al. Miniscrews in orthodontic treatment: review and analysis of published clinical trials. Am J Orthod Dentofacial Orthop. 2010;137(1):108-13.

18. Rossi M, Bruno G, De SA, et al. Quantitative $C B C T$ evaluation of maxillary and mandibular cortical bone thickness and density variability for orthodontic miniplate placement. Int Orthod. 2017;15(4):610-24.

19. Topouzelis N, Tsaousoglou P. Clinical factors correlated with the success rate of miniscrews in orthodontic treatment. International Journal of Oral Science. 2012;4(1):38-44.

\section{Publisher's Note}

Springer Nature remains neutral with regard to jurisdictional claims in published maps and institutional affiliations.

\section{Submit your manuscript to a SpringerOpen ${ }^{\circ}$ journal and benefit from:}

- Convenient online submission

- Rigorous peer review

- Open access: articles freely available online

High visibility within the field

- Retaining the copyright to your article

Submit your next manuscript at $\boldsymbol{\nabla}$ springeropen.com 